\title{
Polymyositis and complete heart block
}

\author{
JOHN M. REID AND RONALD MURDOCH
}

From the Department of Cardio-Thoracic Surgery, Mearnskirk Hospital, Glasgow, and the Department of Medicine, Heathfield Hospital, Ayr

SUMmaRY The development of complete heart block is described in a patient with polymyositis. The implantation of a permanent pacemaker has controlled the heart block, but the progression of the underlying disease despite treatment with relatively high dosage of corticosteroids makes the outlook uncertain.

Although involvement of the myocardium in polymyositis has been recorded (Garcin et al., 1955), cardiac involvement is a relatively uncommon accompaniment in this condition (Hill and Barrows, 1968). The association of complete heart block and polymyositis is exceptional, and we wish to record such an event occurring in a patient four years after the onset of muscle pain and weakness.

\section{Case report}

A man aged 37 years first developed pain and stiffness in both thighs in 1973. This was followed by effusion in the right knee joint. Examination on admission to hospital revealed pronounced muscle wasting in both thighs. The latex test for rheumatoid arthritis, ASO titre, WR and VDRL, ESR, serum calcium and phosphate, alkaline phosphatase, protein electrophoresis, and thyroid scan were all negative, as was radiological examination of the spine and both knees. Subsequently the creatinine kinase $(\mathrm{CK})$ was found to be increased at $644 \mathrm{mIU} / 1$ (normal $<50 \mathrm{mIU} / \mathrm{l}$ ), and muscle biopsy showed foci of muscle fibre necrosis and regeneration, associated with patchy interstitial chronic inflammatory infiltrate. The appearances were consistent with polymyositis, and treatment was instituted with prednisolone, starting with $100 \mathrm{mg}$ daily and reducing to $20 \mathrm{mg}$ daily as maintenance. His condition over the next four years alternated between remissions and relapses necessitating temporary increases in the dosage of corticosteroids. The CK remained persistently high in the range 644 to $5400 \mathrm{mIU} / 1$ and the aldolase was greater than $60 \mathrm{mIU} / 1$ (normal $<50 \mathrm{mIU} / 1$ ). At no time was there any skin involvement. Serial electrocardiograms remained normal from 1973 until mid 1976, when the first evidence of conduction disturbance was noted on the electrocardio- gram. The PR interval was $0.18 \mathrm{~s}$, there was left axis deviation with a $Q R S$ axis of $-60^{\circ}$, there was poor progression of the $R$ wave in right praecordial leads, absence of $Q$ waves in left praecordial leads, QRS of $0.16 \mathrm{~s}$, and the resting heart rate was 55 per minute. He remained symptom-free until mid 1977, when he began to experience dizziness accompanied on several occasions by temporary loss of consciousness. On admission to hospital the electrocardiogram now showed complete heart block, with a ventricular rate of 32 per minute, right axis deviation, and the QRS was $0.20 \mathrm{~s}$. Facilities were not available at the time to perform intracardiac electrocardiography to try and define more precisely the exact site of the block. There were no murmurs audible on auscultation, and chest $x$-ray film showed no cardiac enlargement. A permanent lithium iodide (Medtronic 5972) pacemaker with endocardial electrode was inserted without incident. When reviewed 6 months later, he was pacing satisfactorily. However, because of generalised muscle weakness and high CK levels, the dosage of corticosteroids had to be increased once more.

\section{Discussion}

Various complications may ensue during the course of polymyositis, including ophthalmoplegia, interstitial pulmonary fibrosis, renal failure, and carcinoma of colon (Vukotic and Bozovic, 1975). Cardiac involvement, however, is uncommon (Babka and Pepine, 1973). These authors reported the development of a hyperkinetic cardiovascular state, with congestive cardiac failure refractory to treatment with digoxin and diuretics, in a patient with polymyositis. At necropsy the heart was microscopically normal and excess catecholamines released by degenerating muscle were postulated as the cause of the hyperkinetic state. Lynch (1971) 
reported the development of complete heart block in a patient three years after the onset of the first symptoms of polymyositis. Treatment with corticosteroids and the implantation of a cardiac pacemaker produced only temporary benefit, and the patient died suddenly shortly afterwards. Detailed necropsy studies revealed replacement fibrosis of cardiac muscle fibres in both ventricles, no abnormality in the atrioventricular node, but some fibrosis in both the bundle of His and its two major branches.

In our patient heart block was first noted four years from the onset of muscle weakness, though the electrocardiogram one year previously had indicated the onset of conduction disturbance. There was first degree block, possible left anterior fascicular block, and early left bundle-branch block. There appeared to be no other cardiac involvement and there was no cardiomegaly, so the outlook should be good now that a pacemaker has been implanted. Though high-dose corticosteroids have suppressed the symptoms of polymyositis to date, the per- sistence of raised levels of both $\mathrm{CK}$ and aldolase indicate continuing progression of the underlying disease process, and the long-term prognosis remains problematic.

\section{References}

Babka, J. C., and Pepine, C. J. (1973). Hyperkinetic cardiovascular state in polymyositis. Chest, 64, 243-246.

Garcin, R., Lapresle, J., Gruner, J., and Scherrer, J. (1955). Les polymyosites. Revue Neurologique, 92, 465-510.

Hill, D. L., and Barrows, H. S. (1968). Identical skeletal and cardiac muscle involvement in a case of fatal polymyositis. Archives of Neurology, 19, 545-551.

Lynch, P. G. (1971). Cardiac involvement in chronic polymyositis. British Heart fournal, 33, 416-419.

Vukotic, D., and Bozovic, D. (1975). Dermatomyositis and changes in the heart (in Croat). Reumatizam, 22, 211-220.

Requests for reprints to Dr John M. Reid, Department of Cardio-Thoracic Surgery, Mearnskirk Hospital, Newton Mearns, Glasgow G77 5RZ. 